\title{
Understanding the demographic dividend in Ghana, Sierra Leone and The Gambia: Prospects or missed opportunities?
}

\author{
Stephen Owusu Kwankye ${ }^{1}$ \\ Faustina Frempong-Ainguah ${ }^{1 *}$ \\ Eric Arthur ${ }^{2}$ \\ Eugenia Amporfu ${ }^{2}$
}

\begin{abstract}
This study provides a comparative investigation of the onset of the Demographic Dividend (DD) in Ghana, Sierra Leone and The Gambia. The paper examines the onset of the window of opportunity for harnessing the first $D D$ in the three countries to inform relevant policy actions to reap its benefits. The study uses the National Transfer Accounts Approach, which measures at the aggregate level how individuals at each age acquire and use economic resources by examining the demographic transition alongside economic development in each country. The goal is to determine the commencement of the DD and its implications for policy action. While the window of opportunity of harnessing the labour DD of Ghana started in 1980s and expected to end in 2025, that of The Gambia and Sierra Leone began in 2000 and 2003 respectively, estimated to end by 2050. Sierra Leone and The Gambia have thirty years to make good use of this window of opportunity. Ghana on the other hand according to the data used has barely six years to harness this window of opportunity. This calls for strategic investments in productive sectors to position the countries to reap the benefits of the DD. The analysis suggests that the window of opportunity of harnessing the DD could be a prospect or missed opportunity, which will vary across the three countries with Ghana's opportunity fast running out.
\end{abstract}

Keywords: Demographic dividend; Ghana; Sierra Leone; Gambia; Prospects; Missed opportunities

\footnotetext{
${ }^{1}$ University of Ghana, Regional Institute for Population Studies. *corresponding author Email: ffrempong-ainguah@ug.edu.gh

${ }^{2}$ Kwame Nkrumah University of Science and Technology, Department of Economics and Industrial Management.
}

Ghana Journal of Geography Vol. 13 (1), 2021 pages 25-49

https://dx.doi.org/10.4314/gjg.v13i1.2 


\section{Introduction}

The concept of the Demographic Dividend (DD) describes the process of accelerated economic opportunity and growth that accompanies the changes in a country's population age structure as it moves through the demographic transition from high to low death and birth rates (Bloom \& Williamson, 1998; Gribble \& Bremner, 2012). While all countries are expected to go through a process of transition from high to low death and birth rates, the onset of the DD along the transition is conceived to occur at different points in time and seen as a great opportunity and challenge for most developing countries. This paper attempts an analysis of the timing of the onset of the DD in three West African countries: Ghana, Sierra Leone, and The Gambia. This is aimed at highlighting the relevance of the changing population age structure and the ratio of the working-age population to dependents for identifying the timing of the DD. This could either be a prospect or a missed opportunity and would inform development planning programming activities in these countries using the National Transfer Account (NTA) methodology (Mason et.al., 2009; United Nations, 2013). The NTA approach seeks to improve our understanding of how population growth of any country and how the changes in its age structure influence economic growth, generational equity, and other important features of the economy.

Development is multifaceted and is generally concerned with improving the wellbeing of a country's population. Economically, development can be classified as an increase in gross domestic product that is expected to improve people's living conditions. With a demographic lens, however, development could describe a decrease in both mortality and fertility rates, which will in turn translate into increasing quality of life of the population. A socially developed country will have a higher proportion of its population being literate, having access to quality and affordable healthcare, and eventually higher life expectancy. The demographic dividend is a probable economic opportunity created by changes in the population age structure due to a decline in mortality and fertility and an increase in the ratio of working-age population to non-working age dependents. Although benefits of the demographic dividend have been realised by some Asian and Latin American countries, this is yet to happen in many subSaharan African countries (Gribble \& Bremner, 2012).

There are two types of demographic dividend: a labour force dividend and a savings dividend. The labour force dividend, which is the focus of this paper, emphasises the labour supply effects of changes in a country's age structure. This dividend arises from the increases in the ratio of working-age adults to non-working age dependents. This demographic dividend for 
any economy is temporal and the per capita production will only rise if the labour market can absorb the increasing number of working adults. According to the ILO (2019), paid work is the key driver of material well-being, economic security, equality of opportunities and human development. Unfortunately, advances in these areas tend to elude many people in sub-Saharan Africa (SSA). Harnessing this DD requires early investments in health, education and economic policies/interventions that can absorb the increasing labour supply of the youth into the economy, and allowing people to save and invest in their future.

Although fertility rates in developing countries are falling, they are still high compared to countries in the developed North. The World Bank (2015) observed that fertility decline in Africa has been very slow, resulting in a rapid increase in population, projecting the region to have a much bigger share of the future global population than it has today. The World Bank further reports that Africa will contain 2.8 billion of the world's projected 10 billion population by 2060 compared to 5.2 billion in Asia, 1.3 billion in the Americas, 0.7 billion in Europe, and 0.1 billion in the rest of the world. Rapid population growth rate in a country has implications for economic development. This rapid growth in the population that characterizes the population dynamics of most of sub-Saharan Africa's countries does not necessarily spell doom for the countries in the region. This is because closely linked with the current growth of the population of most of these countries is the emergence of a demographic dividend that must be identified and harnessed for sustainable development. The Demographic Dividend is typically revealed through the changing population pyramid from a broad base to one with a shrinking base, increasing labour force and a decreasing age dependency ratio. This is aptly described as the "youth bulge" (Fluckiger \& Ludwig, 2018; Jimenez \& Murthi, 2006), which demonstrates an increasing number of young people entering the labour market every year for whom the country will need to find jobs. Many sub-Saharan African countries either are beginning to witness this situation or are already in it. Thus, the rapid population growth could hinder or promote economic growth depending on the policies put in place by the various governments in Ghana, Sierra Leone and the Gambia to support this rapid growth.

Previously, rapid population growth discourse was primarily about whether population growth affects aggregate economic development (An \& Jeon, 2006; Barro, 1991; Boserup, 1965; Grossman \& Helpman 1991; Malthus, 1817; Solow, 1956). There have been divergent views: those who believe rapid population growth restricted economic growth (Barro, 1991, Solow, 1956, Malthus, 1817) and proponents who are convinced it promotes economic growth (Boserup, 1965; Canning et al., 2015). Recent studies in development economics and human 
geography recognise population as central to the discourse about economic growth, dealings with their environment and development (Bloom et al., 2003; Canning et al., 2015; United Nations 2013; Peterson, 2017). Canning et al. (2015) argue that population growth through improved health and longevity, can for instance, have different economic consequences compared to population growth through high fertility rates. A healthy population with citizens living longer tends to be beneficial for the economy, while high fertility tends to increase population without increasing productivity in the short-term, thereby lowering income per capita. High fertility also leads to high child dependency rates, reducing the availability of resources per child to invest in improving their health, education, as well as enhancing the quality of the environment and overall wellbeing. The rapid growth in Africa's population varies within the sub-regions and across different countries. Most sub-Saharan African nations are at a critical point in their economic development, with serious challenges of poverty and inequality (Fosu, 2015; 2018); unemployment, under-employment and vulnerable employment also remain high (Baah-Boateng, 2015; ISSER, 2018; ILO, 2019). Globally, the gap in the labour force participation rates between men and women stands at 27 percentage points. While three out of every four men in the labour force are employed, for women, it is less than two of every four that are employed (ILO, 2019). Besides, the employment conditions remain poor in most countries (ISSER, 2018). Thus, the argument about the labour force demographic dividend (herein after referred to as demographic dividend) becomes very important within this context.

The relevance of the demographic dividend is key to four sectors of every country's development. These sectors include the economy, health, education, and governance as well as the environment. Ahmed (2015) argues that Africa's demographics could account for 11-15 percent of the region's gross domestic product growth between 2011 and 2030 with a variation across different countries. According to the World Economic Outlook Database (IMF, 2018), per capita gross domestic product (GDP) for Africa ranges highest for Seychelles and lowest for Malawi. Ghana, Sierra Leone and The Gambia ranked as $17^{\text {th }}, 35^{\text {th }}$ and $37^{\text {th }}$, respectively. It is further projected that because of demographic changes, Africa's poverty rate, which stood at 52 percent in 2007, could reduce to 17-37 percent, made up of 210-451 million poor people (Ahmed, 2015). Quite clearly, this shows the possible impact of the onset of the demographic dividend in each country and how it could be appropriated for the country's benefit. It means that depending on the way the demographic dividend is managed and responded to by policy interventions, more people would be taken out of poverty or be plunged deeper into poverty. 
In the health sector, declining birth rates are expected to have a reducing effect on infant and child mortality, increase life expectancy at birth and further increase the population's potential for production and wealth creation as the national expenditure reduces. It will also require strategic investments in education while ensuring transparent, participatory and accountable governance to reap the benefits associated with the demographic dividend. However, currently, there is limited knowledge on the timing of the demographic dividend in many African countries due to the varying socio-cultural, economic, demographic and political situations in these countries. The timing of the onset of the demographic dividend is also linked to the demographic transition in each country within the context of their respective socio-political economy.

A country's endowed natural resources within its geographical location and good governance, in addition to prudent economic management, education, health care and population policies being implemented might help shape its preparedness in harnessing the first demographic dividend. Although Ghana, Sierra Leone and The Gambia are within tropical West Africa and experience very similar climatic conditions, their topography, land size, population density, development planning activities, stage of demographic transition, health care, educational policies and systems of governance are different and may contribute differently in understanding the timing of their demographic dividend. Figure 1 shows the locations of the study countries within the West African sub-region.

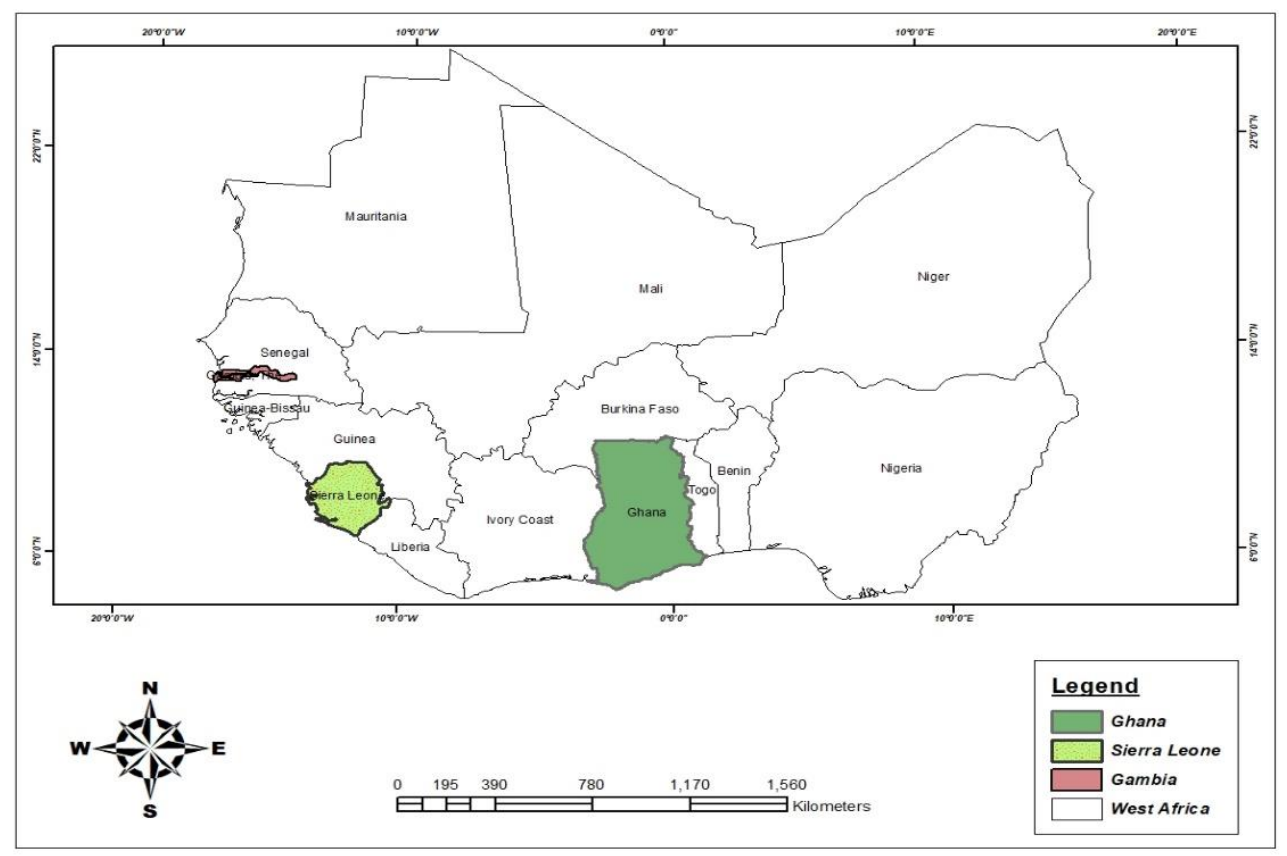

Figure 1: Map of West Africa showing the location of The Gambia, Ghana and Sierra Leone. Source: authors' construct using ARC GIS software. 
Pictorially, The Gambia is the smallest among the three countries in terms of land size. It occupies an area of 10,689 square kilometres and is bordered to the north, south and east by Senegal and to the west by the Atlantic Ocean. Surprisingly, it also has the highest population density of 176 inhabitants per square kilometre as of 2015. Sierra Leone, on the other hand, has a total land area of 71,740 square kilometres, but has the lowest population density of 89.9 persons per square kilometre. Sierra Leone is bordered on the north-east, north and north-west by Guinea, and on the south-east by Liberia and south-west and west by the Atlantic Ocean. In contrast, Ghana is centrally located in West Africa and is the largest of the three countries, occupying a total land size of 238,537 square kilometres, with an average population density of 114 persons per square kilometre in 2015. It is bordered by Burkina Faso to the north and northwest, La Cote d'Ivoire to the west, Togo to the east and the Gulf of Guinea to the south. In terms of topography and vegetation, Sierra Leone is a low-lying country and divided into four distinct regions: the coastal plain that extends inland from the Atlantic Ocean for about 80 metres and very swampy, the Sierra Leone Peninsula, the interior plains and the mountain region. The country has a dense drainage system with nine major rivers and a series of coastal creeks and streams. Ghana is also characterized by low-lying and mountainous regions typically the Akwapim-Togo ranges with the highest elevation at Mountain Afadjato. Ghana also has three distinct ecological zones as the coastal shrub, middle forest belt and northern savanna. The country is drained by several large rivers notably the Black and White Volta. On the other hand, The Gambia is mostly drained by the River Gambia, with mangrove swamps on both sides of the river from the sea. The Gambian economy is heavily reliant on agriculture and tourism. The main natural resources include clay, fish, silica sand, titanium, tin ana zircon. The main exports are groundnuts, fish, cashew and mango among others. Just like The Gambia, Sierra Leone is largely an agrarian economy and heavily endowed with minerals such as diamonds, bauxite, gold, iron ore, rutile, and zircon among others. However, due to the several years of civil war the country experienced since 2005, it is now rebuilding its infrastructure and the economy as a whole. Much progress has been made and considerably among them is the fact that they were able to conduct their national population census in 2015. Ghana on the other hand, is endowed with timber, bauxite, gold, diamonds, manganese and oil. However, notwithstanding these natural resource endowments in these countries, they are all heavily dependent on international aid and/or finances.

The timing and magnitude of the demographic dividend for the three countries in this study depends on some variables. One of these variables is whether the various countries' falling fertility has helped to accelerate economic growth by reducing the proportion of dependent 
children below age 15 years in the population relative to the proportion of the working-age population (15-64 years). In addition, there is the question as to whether the new entrants into the working-age group have been productively employed. Conventional analysis based on demographic and economic computations of the population classified as dependent relies on fixed age groups, often classifying dependents as those individuals less than 15 years and persons aged 65 years and older (Hobbs, 2004: 160). Although this is helpful, Mason et.al., (2009) and United Nations (2013) present an alternative approach using the National Transfer Account (NTA) procedure. This approach identifies variations in the extent of the dependency among the various age groups by examining actual labour income earned for every individual in the population as against the same person's consumption. NTA provides a systematic, comprehensive and coherent way of accounting for economic flows from one age group to another, typically, for the entire population within a given calendar year. This is a more appropriate approach to analyse economic dependency than the conventional categorisation of working and non-working persons simply based on their ages.

Against this background, we examine the onset of the window of opportunity to harness the demographic dividend in Ghana, Sierra Leone and The Gambia using the NTA approach to understand how the differences among the three countries could inform respective policy and programme initiatives towards realising the sustainable development goals (SDGs). We specifically aim to examine the income and consumption profiles in relation to age in each of the three countries. We further analyse the life cycle deficit and surplus in each country; and discuss the economic support ratio which demonstrates the support of the effective working population for 100 non-working population as a consequence of the built-in dependency emanating from the changing age structure in each country depicting the onset of the demographic dividend.

The choice of the three countries is first based on their geographical location in the West African Region and are all English-speaking. Secondly, the three countries were involved in a training workshop in Ghana on the NTA that aimed at equipping national-level experts on the application of the NTA methodology in analysing the possible implications of their respective country's socio-demographic situation as they affect development. There are variations within and across the different countries. The rapid population growth rate can be attributed to the high total fertility rate (TFR) and low contraceptive prevalence rates of 27 percent, 16 percent, and 8 percent respectively for Ghana, Sierra Leone and The Gambia (GSS et al., 2014; SSL \& ICF International, 2014; GBOS \& ICF International, 2014). Like many African countries, 
Ghana, Sierra Leone and The Gambia are currently in the early stage of the demographic transition with fast falling childhood mortality, but not so steady decline in fertility rate. Although the pace and magnitude of the fall are different for the three countries under consideration, , this has enormous implications for the economic development of the sub-region because of the changes that it brings into the age structure of their respective populations, the political will and stability it enjoys to execute sound policies such as good healthcare and education that is expected to contribute towards the development of the skills and potential of this increasing youth population for an economic dividend.

Thus, considering that by their geographical location within the same sub-region, the three countries enjoy relatively similar physical, vegetational and climatic conditions; their differences in demographic dynamics would be helpful in understanding the onset of the demographic dividend relative to how each country would be able to reap its benefits through the adoption of relevant policies and interventions.

\section{Data and Methodology}

\section{Data sources}

The age profile allocation was derived using the 2013 Ghana Living Standard Survey (GLSS). This is a nationally representative survey of 8,687 urban and rural households and 37,128 household members in Ghana. It was carried out by a series of detailed household interviews conducted by the Ghana Statistical Service (GSS) over a 12-month period. Detailed information was collected on demographic characteristics of respondents and all aspects of living conditions including health, education and housing. Information on private expenditure composed of food and non-food items while income comprises of total value of all earnings of production attributable to labour of each country's residents (employed and self-employed incomes). The survey collected household-level data on household size; and individual-level data on age in years, wage income, self-employment income, level and costs of education, health status, number of visits to health facilities and costs of treatment. In addition, we use data from the ministries of finance, education and health to compute the public expenditure on the various age groups, and we use the three most recent population and housing censuses conducted in 1984, 2000 and 2010.

In the case of Sierra Leone, we used the 2011 Sierra Leone Integrated Household Survey (SLIHS), which is comparable to the living standards surveys conducted in Ghana. This a nationally representative survey with complete interviews for 6,767 households in Sierra Leone 
conducted in 2011 (Statistics, Sierra Leone, 2014). The Sierra Leone data were used to estimate household income, consumption and expenditure as well as poverty levels in the country. The survey combines estimates of household income and consumption over a period of one year. We use these to estimate age profiles of the various NTA variables, which are adjusted proportionally to ensure that their aggregate values, conditional on the Sierra Leone population structure in 2011, match the corresponding aggregate totals in the National Accounts where these are available, which we obtained from the 2010-2016 Ministry of Finance and Economic Development financial reports. To estimate the age profile for public health expenditure for Sierra Leone, we used data from the Health Finance Report from the Ministry of Health and Sanitation (2010-2011). We also used the Ministry of Education, Science and Technology's 2010/2011 Annual School Census Report for the public education profile. For the demographic data, we used the three most recent population and housing censuses conducted in the three countries. In the case of Sierra Leone, we used the 1985, 2004 and 2015 population and housing censuses information.

The data for The Gambia are from the 2015/16 Integrated Household Survey (IHS) and private consumption on health, education and other expenditures covering 4,800 households with comparable indicators as found in the GLSS and the Sierra Leone IHS (Government of Gambia, 2011). Detailed information was collected on demographic characteristics of respondents and all aspects of living conditions including health, education and housing. Information on private expenditure composed of food and non-food items, while income comprises of employment and self-employment. The purpose of the survey was to provide identification of policy target groups. This was meant to provide a mechanism whereby key poverty indicators could be easily and regularly produced in order to describe and monitor the well-being of different categories of households. In addition, it helped to provide some key data on how the economic policies affect the availability and quality of social and economic services to households. The survey combines estimates of household income and consumption over a period of one year.

The three surveys that provided the data for the analyses are, therefore, comparable, having collected identical variables and indicators appropriate for the kind of analysis done in the study. For the demographic data, we used population estimates from the World Population Prospects for single age by country for the years 1950 - 2015 (United Nations, 2017). We, however, used data from the three most recent population and housing censuses conducted in the three countries to validate the information obtained from the United Nations Department of Economic and Social Affairs Population Division. For Ghana, we used the 1984, 2000 and 
2010 censuses; for Sierra Leone, the 1985, 2004 and 2015 censuses were used and for the Gambia, we made use of the 1985, 2005 and 2015 rounds of censuses.

In addition, we used data from the various sectors of education, health and finance to compute the age profiles of public spending on education, health and other goods. We matched the corresponding aggregate totals in the National Accounts to the data obtained covering the period 2010-2016. The variables of interest were education, health and other forms of household consumption, each classified as public and private and how they are allocated according to individual ages in the population.

Data used to generate the education profiles were taken from enrolment at the different levels including the primary, secondary and tertiary. Each of these institutions were related to the public and private expenditures at the respective levels. Similar indicators were generated for the health profiles at the out-patients, in-patients, cost of drugs and medication as well as the labour income. There were also age profiles on labour consumption, based on wages and salaries as well as self-employment income. We used these pieces of information to estimate the single age profiles of the various NTA variables, which are adjusted proportionally to ensure that their aggregate values reflect their respective country population structures.

\section{Methods of analysis}

The study uses the NTA method of analysis in presenting the results. The NTA is a comprehensive system for measuring economic resource flows across ages, done at the aggregate level and for a prescribed period (United Nations, 2013). In the NTA, the individual is the fundamental analytic unit. All transactions are treated as flowing to (inflows) and flowing from (outflows) individuals and are classified based on the age of those individuals. In the NTA approach, inflows to one age group (x) should equal outflows from that same age group. The inflows are made up of labour income, transfer inflows, capital income, and property income. The outflows on the other hand are made up of consumption, transfer outflows, property income outflows, and savings. This is summarized in equation (1) as:

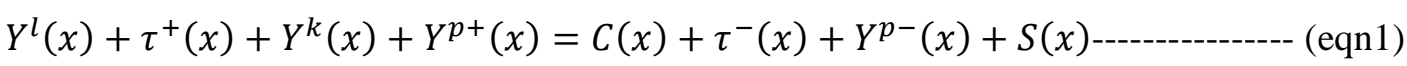

where,

$\mathrm{Y}^{1}, \tau^{+}, \mathrm{Y}^{\mathrm{k}}$ and $\mathrm{Y}^{\mathrm{p}}$ refer to labour income, transfer inflows, capital income and property income, respectively for each age $\mathrm{x}$. 
$\mathrm{C}, \tau^{-}, \mathrm{Y}^{\mathrm{p}-}$ and $\mathrm{S}$ refer to consumption, transfer outflows, property income and savings, respectively for each age $x$.

Aggregating equation (1) yields the profiles for all ages producing equation (2) where the left-hand side represents national disposable income and the right-hand side represents the net of consumption and savings.

$Y^{l}+Y^{k}+Y^{p}+\tau=C-S$ (eqn2)

Rearranging equation (2) gives equation (3).

$C(x)-Y^{l}(x)=Y^{A}(x)-S(x)+\tau^{+}(x)-\tau^{-}(x)$

The left-hand side of equation (3) represents lifecycle deficit for age group $\mathrm{x}$. The life cycle deficit (LCD) is defined as Consumption (C) less Labour Income $\left(\mathrm{Y}^{1}\right)$. The LCD is positive during the dependent years and negative during the working years of the person. The right-hand side gives the assets-based reallocations within the age group $\mathrm{x}$

$\left(Y^{A}=Y^{k}+Y^{p+}-Y^{p-}\right)$. Equation (3) can further be aggregated as

$C-Y^{l}=Y^{A}-S+\tau^{+}-\tau^{-}$

Equation (4) presents the key variable of interest, which is $C-Y^{l}$ and is defined as the lifecycle deficit (the difference between consumption and labour earnings at each age). In this equation, inflows consist of labour income $\left(Y^{l}\right)$, capital and property income inflows $\left(Y^{A}\right)$, and transfer inflows $\left(\tau^{+}\right)$. On the other hand, outflows consist of consumption $(\mathrm{C})$, savings $(S)$, transfer outflows $\left(\tau^{-}\right)$, and property income outflows. Thus, equation (1) states that the difference between consumption and production, known as the life cycle deficit (LCD), must necessarily equal age reallocations, made up of assets-based reallocations and net transfers.

In this study, we provide estimates of the Demographic Dividend. First, we compute the consumption and income profiles per capita, the life cycle deficit and the economic support ratios for each of the three countries. The Demographic Dividend is then computed as the growth of the economic support ratio. The National Income Accounts (NIA) "equivalent" of the NTA components were obtained from the World Development Indicators. The values that are consistent with the national income accounts are then regarded as the aggregate control that is used in the estimates. Aggregate consumption expenditure was further decomposed by purpose: education, health, and other expenditure items for both the private and public sectors. 


\section{Results}

\section{Demographic Transition of the three countries}

Figure 2 presents the population distribution by broad age groups for Ghana, Sierra Leone, and The Gambia between 1985 - 2015. The figure shows that all the countries are experiencing high fertility although there are some variations as depicted by the changing age structure by broad age groups. From Figure 2, we deduce that the demographic transition in Ghana is quite different from the two other countries. This is because it shows clearly that the age structure of Ghana's population has witnessed quite visible changes in comparison with the other two countries. The population below 15 years has reduced from a high of 45 percent in 1984 to 41 percent and 38 percent respectively in 2000 and 2010. This compares with Sierra Leone's population, which remained almost the same during the same period, the population less than 15 years having stayed at about 42 percent in both 1985 and 2004, and about 41 percent in 2015. The proportion of the population in The Gambia below age 15 years so far has been the biggest, staying at 46 percent in 1985, 2005 and 2015 with very slight changes.

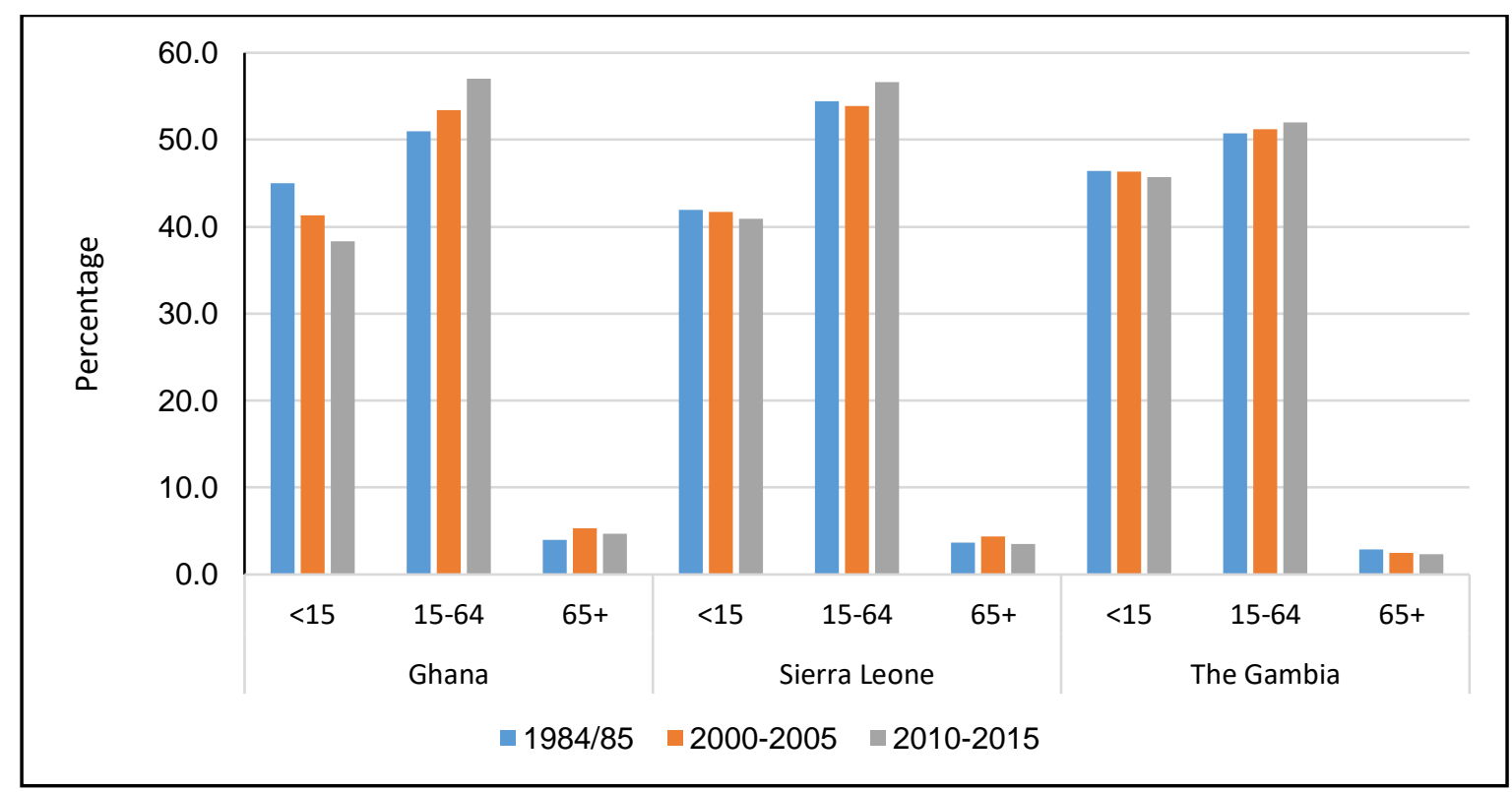

Figure 2: Percentage distribution of population by broad age groups, Ghana, Sierra Leone and The Gambia, 1984 - 2015.

Source: Extracted from the national censuses of Ghana, Sierra Leone and The Gambia for the different years

Figure 2 further shows Ghana again standing out of the two other countries in terms of the changing proportion of the population within the economically active age of 15-64 years. In 1984, the population in this age group was 51 percent, which increased to 53 percent in 2000 and 57 percent in 2010. The steady increase in the working age population in Ghana creates a potential for economic growth. In contrast, Sierra Leone and The Gambia had virtually no 
change in the proportionate share of their population 15-64 years between the first two years as illustrated by Figure 2 (1985-2004 for Sierra Leone and 1985-2005 for The Gambia) before witnessing an increase of almost 57 percent and 52 percent respectively for Sierra Leone and The Gambia respectively in 2015.

The changing age structure also shows that not a significant change occurred in the three countries in the three most recent censuses in these countries. While Ghana's situation indicates an increase in the proportion of the elderly population (65+) from 4.0 percent to 5.3 percent between 1985 and 2000, and a reduction to 4.7 percent in 2010, that of The Gambia steadily declined from 2.9 percent in 1985 to 2.5 percent in 2005 and further to 2.3 percent in 2015 . The situation in Sierra Leone was similar to that of Ghana, with the proportion of the population in this age moving from 3.7 percent in 1985 to 4.4 percent in 2004 but reducing to 3.5 percent in 2015. The dependency ratio in the three countries has changed over the three recent census years. The changes, however, have been more visible for Ghana where it has reduced from as high as 96 percent in 1984 to 76 percent in 2010 compared to The Gambia's 97 percent in 1985 which in 2015 was reported at 92 percent. In contrast, Sierra Leone's dependency ratio, which was about 84 percent in 1985, rose to about 86 percent in 2004 and eventually reduced to about 78 percent in 2015.

The changing age structures of the three countries have obviously come about from the reductions observed in the total fertility rate in the respective countries. So far, Ghana has recorded the lowest total fertility rate which stood at 4.2 in 2014 (GSS et al., 2015), followed by Sierra Leone's 5.2 in 2015 while The Gambia stood at 5.6 in 2013. The three countries are also at different levels of urbanization, which is measured by the proportion of the population reported to be living in urban areas in these countries. About 51\% (2010), 41\% (2015) and 58\% (2013) of the populations in Ghana, Sierra Leone and The Gambia respectively were reported to be resident in urban localities.

These varied demographic indicators of the three countries suggest that they are at varying stages of the demographic transition model, which also signify that they may be experiencing the demographic dividend quite differently. This comes along with varying implications for their respective development. Again, these descriptions are not able to point to the exact timing or onset of the demographic dividend in the three countries. This requires an analysis using techniques that are more appropriate to bring out the critical issues involved. This makes it possible for the making of comparisons that are more realistic among the three countries. The National Transfer Account approach is therefore, considered appropriate in providing the 
answers we need and has been used in this study in the analysis to go beyond trend analysis of changes in the age structure as development progresses.

\section{Per Capita Age Consumption and Income Profiles}

The age consumption and labour income profiles are presented and subsequently used to construct the life cycle deficits. We first present the profiles for total household consumption and then the labour income profiles for the three countries. Figure 3 presents the consumption and income flows per capita in single ages for Ghana, Sierra Leone and The Gambia. The three countries have similar age patterns of consumption. However, the per capita consumption is considerably higher in Ghana and peaks at a much younger age (19 years) than the two other countries. In Sierra Leone, consumption peaks at about age 22 while in The Gambia, it peaks at about age 28. Compared to income, which describes payments for labour, it is lowest at these young ages since those within these ages are mostly in school do not work to earn income. These results, therefore, indicate that there exists a life cycle deficit for the segment of the population below age 25. In addition, consumption is lowest in the middle ages (28-61 years), but income is highest (peaks around age 46 for Ghana, 50 for Sierra Leone and 37 for The Gambia. 


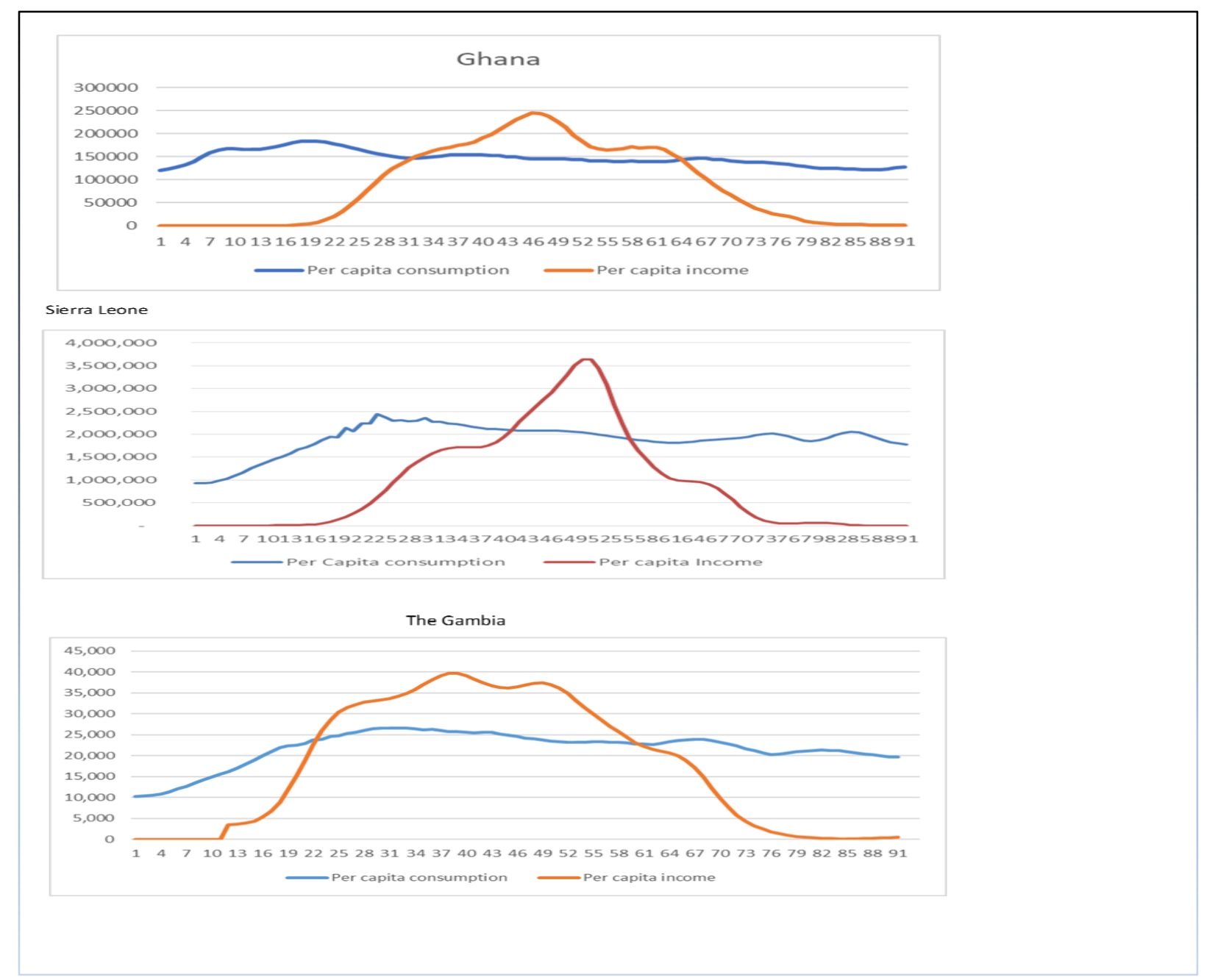

Figure 3: Single age consumption and income flows per capita, Ghana, Sierra Leone and The Gambia

\section{Life Cycle Deficit}

Figure 4 depicts the life cycle of a deficit for Ghana, Sierra Leone and The Gambia at all ages. Where total labour income exceeds consumption at any age, the life cycle deficit is negative and when the reverse is the case, life cycle deficit depicts a positive picture. Figure 4 shows that the life cycle deficit in Ghana is positive during the dependent years $(0-30$ years for younger ages and 65+ for older ages) and negative during a greater part of the working years (31-64 years). On the other hand, the life cycle deficit is positive for Sierra Leone for ages less than 41 years and 56 years and older. It is, however, negative for age groups 41-55 years. In The Gambia (Figure 4), the negative life cycle deficit spans below 22 years and beyond 65 years but positive for individuals aged 22 through to 65 years. 

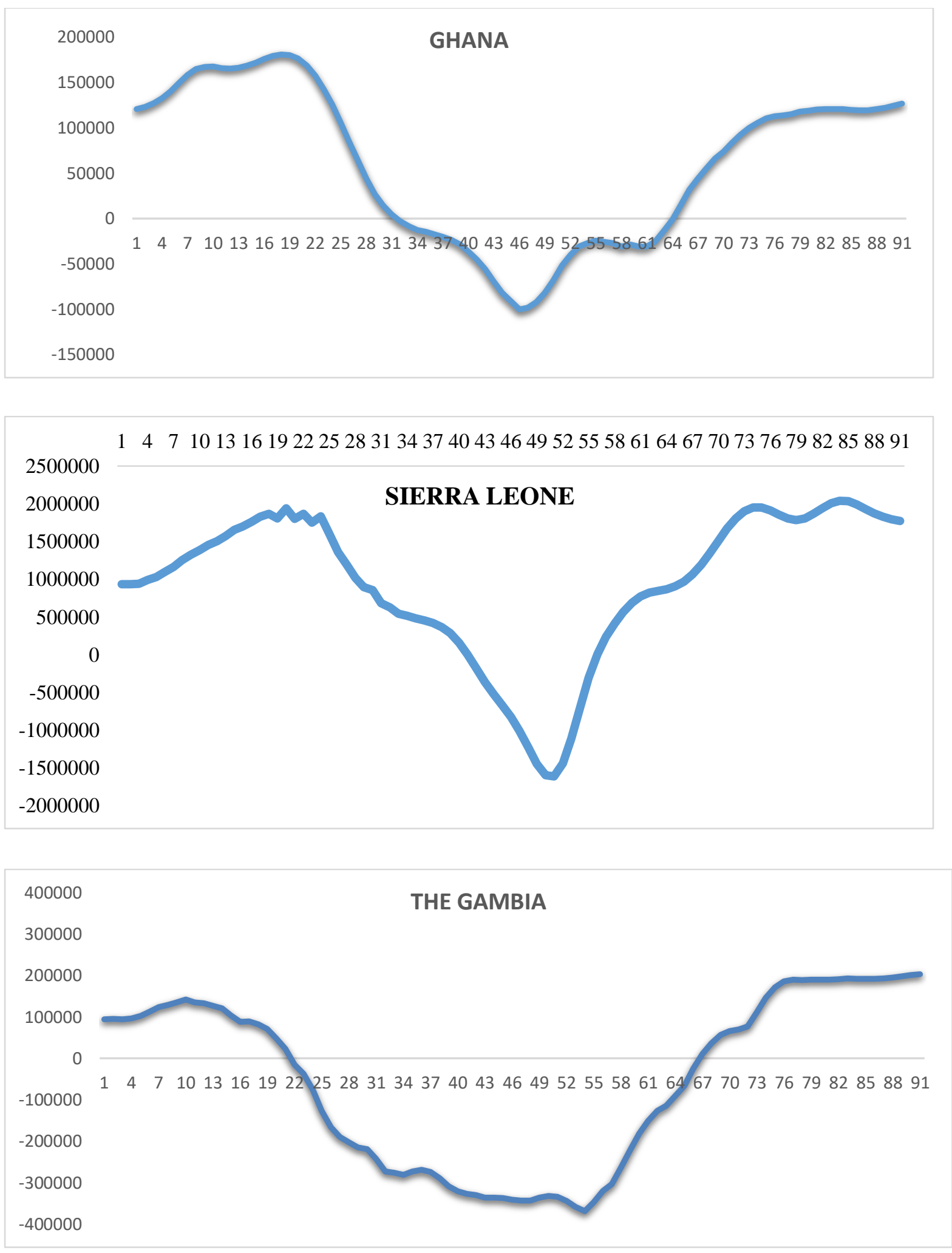

Figure 4: Age-specific Life Cycle Deficit in Ghana, Sierra Leone and The Gambia 


\section{The Economic Support Ratio}

The economic support ratio is calculated as the inverse of the dependency ratio. It shows the extent of support workers provide to non-workers in the economy. The results of the support ratio by year for the three countries are shown in Figure 5. It is realised that the economic support ratio was moderate for all three countries until 1972; however, the variations started with Ghana experiencing a gentle rise, while the other two countries continue to decline steadily until 1992. In 1992, the economic support ratio for Ghana increased steadily, while that of the Gambia experienced a rise but Sierra Leone dropped further till 2011 when the economic support ratio began to increase.

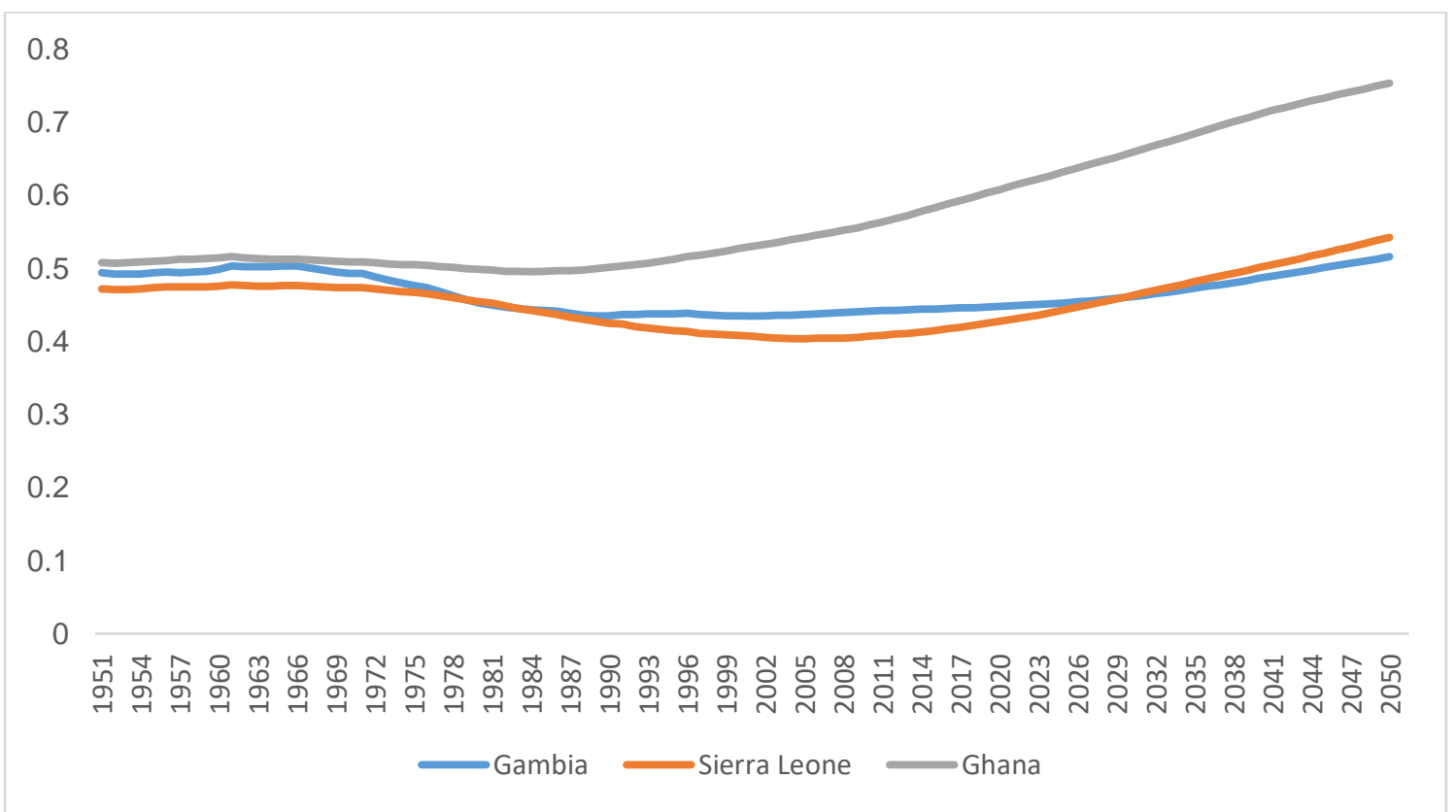

Figure 5: Economic Support Ratio for Ghana, Sierra Leone and The Gambia

From Figure 5, we observe that for all three countries, the support ratio was around 0.5 before 1970, with that for Sierra Leone being slightly lower. This suggests that about half of the population was effectively working to take care of themselves and the other half that was not working in Ghana and The Gambia. In contrast, in Sierra Leone, the proportion of the population effectively working to support the non-working population economically was below 50 percent. Within the 1970s and 1980s, there was some declining support ratios in all three countries, but that of Sierra Leone was higher than that of The Gambia. However, that of Sierra Leone continued to fall below that of The Gambia until after 2023 when both of them are expected to experience a rise in their respective support ratios. In this, Sierra Leone is expected to record a slightly higher support ratio than The Gambia towards 2050. It is interesting to note that even by 2050, the support ratios in both Sierra Leone and The Gambia 
are not likely to be too different from their situations before the 1970s (i.e., the support ratio is slightly higher than 0.5 ).

In contrast, Ghana's situation post-1990 reveals an increasing support ratio which is expected to be higher than 0.7 . This means that the proportion of the population that is expected to work to effectively support the nonworking class is far higher, which is quite a positive development that must be sustained through strategic interventions to record further fertility decline while expanding the productive base of the economy.

\section{The demographic dividend window of opportunity}

As earlier explained, the demographic dividend defines an increase in economic growth due to a fall in fertility, which in turn affects the age structure of the population. A significant reduction in the number of children implies a reduction in the number of dependents, which in turn frees up resources for development and improvement in welfare. With lower fertility every year, the working age population temporarily grows faster relative to the number of dependents thereby creating a window of opportunity for rapid economic growth. This window of opportunity can be harnessed if the right socio-economic policies are developed and investments made, making the demographic dividend a prospect. On the other hand, if this window of opportunity is not well-managed alongside the implementation of right policies and investment it will lead to a missed opportunity to harness the benefits of the demographic dividend. Figure 6 presents the trend of the demographic dividend for the three countries. 


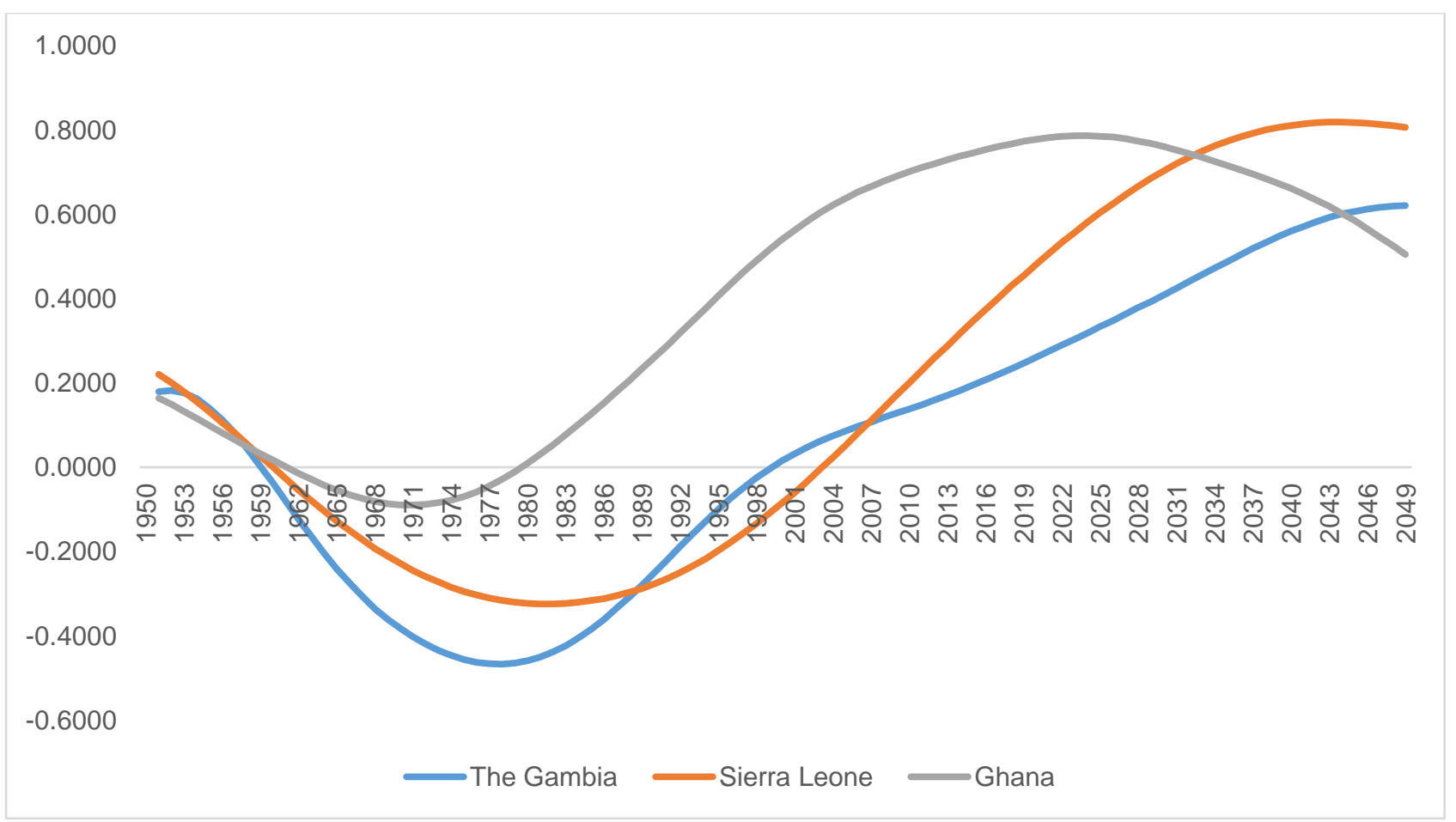

Figure 6: Window of opportunity for harnessing the demographic dividend for the three countries by year

From Figure 6, we deduce that the demographic dividend began in 1984 in Ghana and is expected to end in 2030. In contrast, the demographic dividend started in 2000 and 2003 for The Gambia and Sierra Leone respectively and is expected to end around 2050 for both Sierra Leone and The Gambia.

\section{Discussion}

The demographic dividend has long been viewed as an important component of economic development. It serves as a yardstick for policies that aim at a more balanced age structure through reductions in fertility. Worldwide, people are having fewer children. At the same time, life expectancy is increasing. The transition from high to low fertility implies that the proportion of the young dependent population declines in relation to the working-age group. During the early stages of the demographic transition, the proportion of children below 15 years is high due to high fertility and decreasing mortality rates. In contrast, the population of persons in the working ages (15-64 years) is relatively smaller in proportion with a small proportion of the elderly population beyond age 64 years. As the transition progresses, however, fertility eventually declines, resulting in the shrinking of the population of persons at the younger ages with a gradually increasing working age population while the proportion of the population 
living beyond age 64 increases. The changing ratio of workers and dependents will, thus, ease the pressure on intergenerational transfers.

This change in population age structure brings about a period of an enhanced accelerated economic growth termed as the "first demographic dividend" (Lee \& Mason, 2016; United Nations, 2013). With fewer children, there is less demand on available household and government resources to provide better education, health care, housing, etc., for each child, with surpluses to invest in productive sectors of the economy, thereby improving their standards of living. As fertility continues to decline, the population of children below age 15 years eventually enters the working ages. Consequently, they would require jobs to do; some of the population in the working ages will transition into retirement and may become dependent if they were unable to accumulate enough resources to take care of themselves during their retirement period. At this stage, earlier investments in health, education, and physical capital accumulation can help sustain economic growth, based on a smaller, but more productive workforce. This is the "second demographic dividend" (Mason et al., 2016; United Nations, 2013) which can be more beneficial and long lasting. By providing estimates of labour income and consumption at every age, the National Transfer Accounts (NTA) methodology helps to measure the economic impact of changes in population age structure throughout the demographic transition.

The observed patterns found in the respective countries' age-specific profiles presented in this study show that the higher consumption at the lower ages could be attributed to the higher investment by both government and households in education and health in addition to other expenditures apart from health and education. Compared to income, which is, payments for labour, it is the lowest since those within this age are mostly in school and for that matter cannot work to earn income. Within the middle ages, most people are economically active and, therefore, engage in some form of economic activities to earn income. The income and consumption pattern for the elderly population is like that of the lower ages, except that in this case, the expenditure is mainly on health and other expenditures other than education.

For Sierra Leone, the chart shows that the margin between income and consumption is greater for ages 0-40 years and age 55 onwards. While consumption shows a steady pattern that is almost smooth, income demonstrates a bell-shaped curve like a normal distribution graph. At age 41 years and 55 years, income is higher than consumption and these ages are associated with more responsibility with respect to savings for caregiving for the young and the elderly. The figure shows that consumption patterns for ages below 40 and above age 55 are greater than the income they are generating. This means that the population aged below 40 are 
dependent on age 41-55 years. What the chart depicts is that in Sierra Leone much of the consumption is financed through transfers, as the consumption line is higher than that of income earnings. The few income earners above the consumption line must support those below the consumption line.

From the income and consumption profiles, we find that Sierra Leone is quite different from Ghana and The Gambia with respect to the coverage of the recorded income surplus over consumption. While the income surplus covers a span of about 36 years and 42 years respectively in Ghana and The Gambia, that in Sierra Leone covers just about 15 years. This could be the result of the 11 years of civil war between 1991 and 2002 that might have affected the productive incomes of the working age population in Sierra Leone compared to Ghana and The Gambia, which have had long years of political stability.

The inverse of the age consumption and income profiles is what has translated into the life cycle deficits for the three countries. Of the three countries, The Gambia stands out from the two other countries in terms of the size of the surplus of income over consumption as is depicted in the life cycle deficits.

The results of the changing support ratio analyses for the three countries reflect the different stages they are relative to the demographic dividend in terms of the changing age structure. The analysis of the demographic dividend for the three countries suggests that its onset began far earlier in Ghana compared to Sierra Leone and The Gambia. This is because of the earlier fertility decline Ghana experienced compared to the other two countries. The vast difference between Ghana and the other two countries shows the earlier commencement of the demographic dividend evidenced by the fall in the fertility rate, which began much earlier in the country compared to Sierra Leone and The Gambia. Again, the declining fertility, which has been more visible in Ghana than in the other two countries has led to a higher reduction in the dependency burden that is inherent in the age structure of the countries. As the dependency ratio reduces, we expect a corresponding increase in the support ratio. However, for the benefits associated with the increasing support ratio to be realised, there is need to invest more practically in each country's young human resources while expanding the productive base of the country through strategic investments to make the observed demographic dividend associated with the falling fertility become a prospect for development.

Currently, Ghana's fertility is far lower than that in Sierra Leone and The Gambia. The 2017 Ghana Maternal Health Survey reported a total fertility rate of 3.9 (GSS et al., 2018) compared to 5.2 in Sierra Leone in 2015 (Statistics Sierra Leone, 2017) and 5.6 in The Gambia in 2013 
(The Gambia Bureau of Statistics, 2014). Besides, in terms of economic growth and overall development, Ghana stands taller considering its lower middle-income status. However, Ghana has a much shorter time left for the demographic dividend to close compared to Sierra Leone and The Gambia. Hence, Ghana needs to work harder to invest in the youth to reap the benefits associated with the dividend before it closes, unlike Sierra Leone and The Gambia that have longer years to work towards the hastening of the demographic dividend through sustained fertility decline and strategic investments targeted at the youth.

\section{Conclusion}

This study suggests different timing of the onset of the demographic dividend with different implications for development. Depending on the policy attention on the trend of the demographic dividend, each country stands to benefit differently. It is important that each country pays attention to the different trends shown and respond accordingly with relevant policy interventions, mindful of the timespan for the demographic dividend to close. It should also be noted that efforts towards reaping the demographic dividend should aim at adopting strategic policies and interventions in the economic, education and health sectors while ensuring participatory, transparent and accountable governance, paying attention to the different periods for the opening and close of the demographic dividend window in each of the three countries studied. For Ghana, the time left for the demographic dividend to close is shorter. Thus, a lot would have to be done by way of strategic investments to equip and absorb the large army of youth for productive jobs to make the dividend a development-oriented prospect. If this is not done, it would become a missed opportunity if the right policies and programmes are not pursued. On the other hand, for Sierra Leone and The Gambia, the onset of the demographic dividend is much later, but is projected to last relatively longer before closing. The two countries must, however, invest in family planning to ensure faster fertility reduction to hasten the onset of the demographic dividend before reaping it as a development prospect; otherwise, the demographic dividend may be a missed opportunity that may never be realised.

\section{Ethical Clearance}

The paper used secondary data sources from the three countries; hence we did not come into direct contact with any human subjects. However, prior to the conduct of the Living Standards 
Surveys and the Integrated Household Surveys, the respective countries obtained ethical clearance. Permission was also obtained from the various countries for the datasets including the census information. These together with the administrative data and information are in the public domain that were also used. In addition, we sought permission from the respective institutions for the use of the other institutional data. We attach some of the links to the various main data sources used: Statistics.sl/index.php/what-we-offer/open-data-free-datasets.html, Microdata.workdbank.org/index.php/catelog2943, Gambia 2010-11 Integrated Household Survey, gbs.gov.gm/poverty.php, Statsghana.gov.gh/gssdatadownloadspage.php.

\section{Funding or acknowledgment}

The authors did not receive direct funds to produce the article, however, UNFPA West and Central Africa Office (WCARO) provided funding for the National Transfer Accounts (NTA) technical experts training and the team was contracted to assist Ghana, Sierra Leone and The Gambia to generate their various country profiles from which the paper was conceived. The team also benefitted from technical assistance from the Director of the Regional Excellence Centre in Generational Economy (CREG), based in Senegal during the expert training. The authors are also grateful to the support of country participants from Ghana, Sierra Leone and The Gambia.

\section{Conflict of interest}

The authors declare that there is no conflict of interest in producing this paper.

\section{References}

Ahmed, A.S. (2015). How significant could Africa's demographic dividend be for growth and poverty reduction? https://blogs.worldbank.org/africacan/how-significant-couldafricas-demographic-dividend-be-for-growth-and-poverty-reduction.

An, C. B. \& Jeon, S.-H. (2006). Demographic change and economic growth: An inverted-u shape distribution. Economic Letters, 92, 447 - 454.

Baah-Boateng, W. (2015). Unemployment in Ghana: A cross sectional analysis from demand and supply perspectives. African Journal of Economics and Management Studies, 6, $402-415$.

Bloom, D. E., Canning, D. \& Malaney, P. (2000). Demographic Change and Economic Growth in Asia. Population and Development Review, 26s, 257-290.

Bloom, D.E, Canning, D. \& Sevilla, J. (2003). The Demographic Dividend: A new perspective on the economic consequences of population change. Santa Monica, CA: RAND Corporation. 
Bloom D. E., Williamson J. G. (1998). Demographic Transitions and Economic Miracles in Emerging Asia. World Bank Economic Review, 12, 419 - 455.

Barro, R.J. (1991). Economic growth in a cross section of countries. The Quarterly Journal of Economics, 106, 417 -443.

Boserup, E. (1965). The conditions of agricultural growth: The economies of agrarian change under population pressure. George Allen \&Unwin Ltd, London, UK.

Canning, D., Raja, S., Yazbeck, A. S. (2015). Africa's Demographic Transition: Dividend or Disaster? Africa Development Forum; Washington, DC: World Bank; and Agence Française de Développement. World Bank. https://openknowledge.worldbank.org/handle/10986/22036 License: CC BY 3.0 IGO.

Flückiger, M., \& Ludwig, M. (2018). Youth bulges and civil conflicts:Causal evidence from Sub-Saharan Africa. Journal of Conflict Resolution; 62, 1932- 1962.

Fosu, A.K. (2018). The 2030 agenda for sustainable development on reducing poverty and inequality in Africa: options, challenges and opportunities. Report for the United Nations Economic Commission for Africa (UNECA).

Fosu, A.K. (2015). "Growth, Inequality and Poverty in sub-Saharan Africa: Recent Progress in Global Context”. Oxford Development Studies, Taylor \& Francis Journal, 43, 44 - 59.

Ghana Education Service, (2016). Education Information Management System (EMIS) 2015/2016 Report. Ghana Education Service.

Ghana Statistical Service. (2014). Ghana Living Standards Survey Round 6 (GLSS-6): Main report. Ghana Statistical Service; Sakoa Press Limited, Accra.

Ghana Statistical Service (2012). 2010 Population and Housing Census: Summary report of final results. Ghana Statistical Service; Sakoa Press Limited; Accra.

Ghana Statistical Service (2002) 2000 Population and Housing Census- summary Report of Final Results.' Ghana Statistical Service, Accra.

Ghana Statistical Service (GSS), Ghana Health Service (GHS), and ICF. (2018). Ghana Maternal Health Survey 2017: Key findings. Rockville, Maryland, USA: GSS, GHS, and ICF.

Government of The Gambia (2011). Integrated household survey income and expenditure poverty assessment- 2010; Gambia Bureau of Statistics, The Gambia.

Gribble, J.N. \& Bremner, J. (2012). Achieving a Demographic Dividend. Population Bulletin 67, No.2. www.prb.org.

Grossman, G.M. \& Helpman, E. (1991). Innovation and growth in the global economy. MIT Press, Cambridge, London.

Guengant, J.-P. \& Kamara, Y. (2012). How can we capitalize on the Demographic Dividend? Demographics at the heart of Development Pathways. Synthesis of studies conducted in WAEMU countries and in Ghana., Guinea, Mauritania and Nigeria; A Savoir, AFD Research Department, France.

Hobbs, F. (2004). Age and sex composition. In Siegel, J. S. \& Swanson, D. A (Eds.) The Methods and Materials of Demography. Second Edition. (pp125-174). Elsevier Academic Press, San Diego USA.

Institute of Statistical, Social \& Economic Research (2018) The State of the Ghanaian Economy 2017 report. ISSER, University of Ghana; Sundel Services, Accra, Ghana.

Institute of Statistical, Social \& Economic Research. (2014). Ghana Social Development Outlook 2014. ISSER, University of Ghana; Sundel Services, Accra, Ghana.

International Labor Organization. (2019). World Employment and Social Outlook: Trends 2019. ILO Office- Geneva, ILO.

International Monetary Fund. (2018). World Economic Outlook: Growth Slowdown, Precarious Recovery. Washington, DC, April. 
Jimenez, E.Y. \& Murthi, M. (2006). Investing in the youth bulge. Finance and Development; A Quarterly Magazine of IMF. 43(3).

Lee, R.D. \& Mason, A. (2016). National transfer accounts and demographic dividends. Bulletin; National Transfer Accounts; Number 9, Revised.

Malthus, T.R. (1817). "An Essay on the Principle of Population." Online la.utexas.edu/users/hcleaver/368/MalthusPopCh10table.pdf.

Mason, A., Lee, R. \& Jiang, J.X. (2016). Demographic dividends, human capital and saving. The Journal of the Economics of Ageing. 7: 106 -122. Doi:10.1016/j.jena.2016.02.004.

Mason A., Lee, R., Tung A.-C., Lai, M.-S., \& Miller, T. (2009). Population aging and intergenerational transfers: introducing age into national income accounts. in David Wise, ed., Developments in the Economics of Aging. Chicago: National Bureau of Economic Research; University of Chicago Press; (pp. 89-122).

Peterson, W.E.F. (2017). The role of population in economic development. SAGE publications, 2017: 1-15. Doi. 10.117712158244017736094.

Solow, R.M. (1956). A contribution to the theory of economic growth. The Quartrly Journal of Economics, 70, 65 -94. Https://doi.org/10.2307/1884513.

Statistics Sierra Leone. (2018). Sierra Leone 2015 Population and Housing Census National: analytical report. UNFPA, Sierra Leone.

Statistics Sierra Leone \& ICF International. (2014). Sierra Leone Demographic and Health Survey 2013, Freetown, Sierra Leone and Rockville, Maryland, USA: SSL and ICF International.

Statistics Sierra Leone. (2014). Sierra Leone Integrated Household Survey. SLE-2011SLIHS_V01_M.

The Gambia Bureau of Statistics (GBOS) and ICF International. (2014). Gambia Demographic and Health Survey 2013, Gambia and Rockville, Maryland, USA: GBOS and ICF International.

United Nations. (2013). National Transfer Accounts manual: Measuring and analysing generational economy. Population Division, Department of Economic and Social Affairs; United Nations; New York.

United Nations Department of Economic and Social Affairs, Population Division. (2017). World Population Prospects: The 2017 Revision; DVD Edition.

World Bank. (2015). Africa's population boom: Will it mean disaster or economic and human development gains. https://www.worldbank.org/en/region/afr/publication/africasdemographic-transition 